\title{
A cross-sectional study to compare levels of psychiatric morbidity between young people and adults exposed to violence in a large urban center
}

Denisse Jaen-Varas ${ }^{1 *}$, Jair de Jesus Mari ${ }^{1,2}$, Evandro da Silva Coutinho ${ }^{3}$, Sérgio Baxter Andreoli ${ }^{1}$, Maria Ines Quintana', Marcelo Feijó de Mello ${ }^{1}$, Rodrigo Affonseca Bressan ${ }^{1}$ and Wagner Silva Ribeiro ${ }^{1,4}$

\begin{abstract}
Background: Teenagers and young adults are more exposed to violence and traumatic events than adults, and these factors can be associated with mental disorders. This paper aims at investigating whether young people are more exposed to violence and traumatic events and to compare pattern of mental disorders with adults.

Methods: Cross-sectional study using the Composite International Diagnostic Interview, conducted between 2007 and 2008 with a randomly selected sample of 15 to 75 year-old residents of São Paulo, Brazil.

Results: Two thousand five hundred thirty-six participants were divided into two groups: 1096 (43.2 \%) young people (15 to 24 years), and 1440 (56.8 \%) adults (25 to 75 years). 12-month exposure to traumatic events was higher among young people (32.1 \% vs. $20.6 \% ; p<0.001)$. Assaultive violence was reported by $13.4 \%$ of young people and $8.6 \%$ of adults ( $p=0.012$ ); $20.1 \%$ of young people and $13 \%$ of adults reported suffering other injury or shocking events $(p<0.001)$; sudden death/life threatening illness of a close person was declared by $6.1 \%$ of young people and $3.2 \%$ of adults $(p=0.017$ ). Prevalence of alcohol related disorders was higher among young people (5.4 \% vs. $2.5 \% ; P=0.032)$; depressive disorders were more prevalent among adults $(9.0 \%$ vs. $4.7 \% ; P=0.004)$. Alcohol related disorders were associated to assaultive violence among young people $(\mathrm{OR}=3.4 ; 95 \% \mathrm{Cl}=1.36$ to 8.52; $p=0.004)$ and adults $(\mathrm{OR}=2.38 ; 95 \% \mathrm{Cl}=1.23$ to $4.61 ; p=0.002)$. Phobic/anxiety disorders were associated to other injury or shocking events among young people $(\mathrm{OR}=1.28 ; 95 \% \mathrm{Cl}=0.67$ to $2.44 ; p=0.025)$. Major depressive disorder was associated to assaultive violence among young people ( $\mathrm{OR}=2.27 ; 95 \% \mathrm{Cl}=1.09$ to $4.74 ; p=0.004$ ) and adults $(\mathrm{OR}=1.28 ; 95 \% \mathrm{Cl}=0.85$ to $1.93 ; p=0.009)$.
\end{abstract}

Conclusion: Exposure to violence and traumatic events was higher among young people. Alcohol related disorders, depression and phobic/anxiety disorders were significantly higher among young people exposed to traumatic events. Despite the study design, high exposure to violence and traumatic events in this age group can be considered important factors in triggering mental disorders in this vulnerable age period.

\footnotetext{
* Correspondence: deni_clau@hotmail.com

1 Departamento de Psiquiatria, Universidade Federal de São Paulo, Rua

Borges Lagoa, 570, São Paulo, SP 04038-000, Brazil

Full list of author information is available at the end of the article
} 


\section{Background}

Adolescence is an important stage in human development, and it is characterized by decreased incidence of disease and good average health conditions. However, risky behaviors and life styles that may have long term effects throughout adult life [1-3] are a common during adolescence. Brain development is not complete until the age of 25. Therefore, important hormonal and neurobiological changes in specific brain regions and cell populations $[4,5]$ are still ongoing during adolescence and early adulthood. Moreover, several behavioral changes occur during adolescence that can be triggered and/or intensified by contextual factors, such as community, school and workplace characteristics, as well as peers and family influences [4,6-10]. Adolescence can, therefore, be defined as a turbulent period characterized by impulsivity, sensitivity to peer influence, intensified emotional reactivity, novelty seeking, mood dysregulation, and risky behaviors $[2,5,11]$, which may increase exposure to violence and other traumatic events $[5,12]$. Adolescence is also a peak period for clinical onset of most mental illnesses [5, 6, 13].

Available data suggests that exposure to violence is more prevalent among adolescents and young adults, in comparison to other age groups $[2,14,15]$. The World Health Organization's World Report on Violence and Health [15], for example, estimates that homicide rates in the year 2000 in the age group ranging from 10 to 29 was 9.2 per 100,000 individuals worldwide. According to the same report, in Brazil, $39.7 \%$ of deaths among young people between the ages of 15 and 24 resulted from homicides, whereas, among adults, homicides accounted for $1.8 \%$ of deaths. Among young people, only $26.4 \%$ of deaths result from natural causes, whereas $90.1 \%$ of deaths among adults are attributed to natural causes [15]. Available evidence on exposure to violence, however, predominantly rely on homicide rates, and few studies effectively probe youngster exposure to types of violence that are common in urban centers [16-18].

Population-based studies have identified violence as a major risk factor for the development of mental disorders [18-20], mainly when experienced at an early age and/or when there is an accumulated exposure during the cycle of life $[9,12]$. Exposure to situations such as domestic violence or conflict [21], negative life events [22], persistent threat, bullying [23], parental loss or abuse [21] can have a permanent effect across the person's life [24]. The maturation of the brain during adolescence makes this age group particularly vulnerable to the development of mental disorders $[1,6,14,20,25-27]$, especially because young people are possibly more vulnerable as a result of their greater exposure to violence. It has been proposed that violence can negatively affect brain development, leading to changes to the structure (reduce to volume in the hippocampus, corpus callosum, cerebellum, and a smaller prefrontal cortex.) and chemical activity of the brain (altering neurogenesis, migration, synaptogenesis, and neurochemical differentiation) $[6,8,11,28]$. Evidence has shown that such changes to the brain's structure and chemical activity are associated to several mental health problems $[6,8,29,30]$. This article aims to study how exposure to violence and other traumatic events affects the mental health of young people and adults living in a large urban centre in Brazil. In short, the following hypothesis are tested: a) exposure to violence and traumatic events is greater in young people than adults; and b) young people and adults exposed to violence and traumatic events have different patterns of mental disorders.

\section{Methods}

This article is based on a secondary analysis of data from a one-phase cross-sectional survey that was designed to estimate the prevalence of exposure to traumatic events and of mental disorders in the general population. A detailed account of the study design, sampling strategy and data-collection procedures is provided elsewhere [20]. Briefly, data used in this article was collected in the city of Sao Paulo, which is the largest urban centre in Brazil. The city has over 11 million inhabitants. It is the major industrial, commercial and financial centre in the country, and presents high levels of socioeconomic inequality and violence.

The study was carried out in 2007-2008, and it included a representative sample of residents aged 15 to 75 years, through a multilevel stratified sample strategy. The stratification was based on the homicide rates as follow: firstly, the 96 administrative areas in the city were ranked according to their homicide rates, and then grouped into six strata. Secondly, all census sectors within each stratum were mapped, and then a number of census sectors were randomly selected within each stratum. In the third stage, 43 households were randomly selected within each selected census sector. Finally, in each selected household, one dweller aged between 15 and 75 years was randomly selected based on the Kish's method [20, 31].

Variables of interest were assessed through the Composite International Diagnostic Interview, version 2.1 (CIDI 2.1) [20, 32-34], which was applied at participants' households by trained lay interviewers. To assess exposure to violence and other traumatic events, authors added 20 new types of events to the original 11-event list in the CIDI 2.1 to include experiences that are common in Brazilian urban centres [20]. Lifetime and 12-month exposure to traumatic events were assessed. CIDI 2.1 diagnosis of mental disorders was based on Diagnostic and Statistical Manual of Mental Disorders, $4^{\text {th }}$ Edition 
(DSM-IV). Three diagnoses were selected to study the association between traumatic events and mental disorders in young people and adults: a) alcohol related disorders (Alcohol hazardous use, Alcohol dependence); b) major depressive disorders; and c) phobic/anxiety disorders (panic disorder, specific phobia, social phobia, agoraphobia, generalized anxiety disorder and obsessive-compulsive disorder). Therefore, adolescents and young adults are thought to be at greater risk of being exposed to violence and other traumatic events $[12,17]$.

\section{Statistical analysis}

Prevalence estimates and confidence intervals were corrected according to sampling weights in order to adjust for differences in the probability of participant selection due the study design. The Sample was stratified into two groups, for every analysis: young people (ages 15-24) and adults (ages 25-75). The cut-point (24 years) was defined on the bases that, according to the literature, transition into adulthood is not fully complete before the age of 25 years $[4,6,9]$, and, therefore, biological, social and cultural changes that define adolescence are still ongoing. Such changes could lead to specific vulnerabilities related to impulsivity and risk-taking behaviors that are common among adolescents and young adults [2, 5, 11]. Sample characteristics were described as analysis of frequency. Comparisons between age groups in relation to variables of interest were conducted by means of $2 \times 2$ contingency tables. Statistical significance of differences between groups were estimated through Pearson's Chi Square test, adjusted for sampling weights.

As cumulative exposure to traumatic events tends to increase overtime, it would be expected prevalence of lifetime exposure to be higher among adults than young people as a function of age. Therefore, in order to assess between-groups differences in exposure to violence within a comparable timeframe, we considered only events that occurred in the last 12 months in order to verify whether exposure to traumatic events was higher among young people than adults.

When assessing the effect of exposure to traumatic events on psychiatric diagnoses, only traumatic events that happened more than 12 months prior to the interviews were included in the analyses as independent variables, whereas 12-month estimates of psychiatric disorders were defined as dependent variables. This modelling allowed for the establishment of temporal relationship between exposure to traumatic events and diagnoses in order to avoid reverse causality. The effect of exposure to traumatic events on psychiatric diagnoses was assessed through bivariate and multivariate analyses of association, which were based on the comparisons of proportions of diagnoses among those exposed and those not exposed to traumatic events. We excluded posttraumatic stress disorder (PTSD) because exposure to traumatic events is a mandatory diagnostic criterion, meaning that those who did not report exposure to traumatic events are not eligible to be diagnosed with PTSD.

To test the hypothesis that patterns of association between traumatic events and mental disorder would be different for young people and adults, analyses were stratified in these two age groups, and conducted in three steps: first, a bivariate association between each traumatic event and each diagnostic was estimated through $2 \times 2$ contingency tables. In a second step, multivariate logistic regression models were performed to control the effects of demographic characteristics (gender, marital status, education, occupational situation and migration history) as possible confounding factors. For each diagnosis entered as a dependent variable, the other two diagnoses were also entered in the logistic regression model as independent variables to control the effect of potential comorbidity. In these analyses, traumatic events were grouped into three binary variables (yes or no) that represent the three most relevant types of traumatic experiences according to the literature [20, 35-37]: a) assaultive violence; b) other injury or shocking events, which include indirect exposure to violence and accidents; and c) sudden death/life threatening illness of a close person, defined as a family member, close friend and/or romantic partner. All three types of traumatic events were entered together in the analyses, in order to control for the potential overlapping between them. In the two first steps, analyses were run separately for each age group. In the final step, the logistic regression models were repeated using the entire sample and including an interaction term between traumatic events and age group to assess the statistical significance of differences between Odds Ratios across the two age groups.

\section{Results}

Table 1 presents the sample's demographic characteristics. The final sample comprised 2536 participants, corresponding to $84.5 \%$ response rate. The sample was composed of 1096 (43.2\%) young people aged 15 to 24, and 1440 (56.8\%) adults aged 25 to 75 . Proportion of females was greater in both groups. More adults than young people were married or lived with a partner (63.9\% vs. $25.9 \% ; p<0.001)$. Among young people, the proportion of those with no or low education $(0-4$ years) was significantly lower than among adults $(2.3 \%$ vs. $24 \% ; p<0.001)$. More adults than young people were working at the time the study was done $(62.6 \%$ vs. $50.1 \% ; p<0.001)$. Proportion of migrants was greater in the adult group $(55.0 \%$ vs. $28.0 \%$; $p<0.001)$. As can be seen in Table 2, prevalence of alcohol related disorders 
Table 1 Socio-demographic characteristics of the sample

\begin{tabular}{llll}
\hline & $15-24$ & $25-75$ & $P$ value \\
\hline Gender & & & \\
Male & $227(43.3)$ & $276(41.6)$ & 0.576 \\
Female & $869(56.7)$ & $1164(58.4)$ & \\
Marital status & & & \\
$\quad$ Single & $363(72.5)$ & $354(18.4)$ & $<0.001$ \\
Married/cohabiting & $130(25.9)$ & $1337(63.9)$ & \\
Separated/divorced & $8(1.2)$ & $220(10.7)$ & \\
Widowed & $2(0.5)$ & $122(7.0)$ & \\
Education (years of school) & & & \\
0-4 & $15(2.3)$ & $573(24.0)$ & $<0.001$ \\
5-8 & $155(28.3)$ & $551(24.9)$ & \\
9-12 & $303(60.1)$ & $651(34.1)$ & \\
$\quad$ 13 or more & $30(9.3)$ & $257(17.0)$ & \\
Occupational status & & & $<0.001$ \\
Currently unemployed & $0(0.0)$ & $0(0.0)$ & \\
Currently employed & $246(50.1)$ & $1313(62.6)$ & \\
Migration history & & & $<001$ \\
Being a migrant & $154(28.0)$ & $1231(55.0)$ & \\
\hline
\end{tabular}

was greater in young people than in adults (5.4\% vs. $2.5 \% ; P=0.032$ ), whereas major depressive disorder was more prevalent among adults as compared to young people (9.0 \% vs. $4.7 \% ; P=0.004)$. No differences were detected in the prevalence of phobic/anxiety disorders.

Table 2 also presents the prevalence of exposure to violence and other traumatic events. Exposure to traumatic events in the 12 months before to the interview was significantly higher among young people $(32.1 \%$ vs. $20.6 \% ; p<0.001)$. Exposure to the three types of traumatic events in the 12 months before the interview was greater among young people than adults: exposure to assaultive violence was reported by $13.4 \%$ of young people and $8.6 \%$ of adults $(p=0.012) ; 20.1 \%$ of young people reported suffering other injury or shocking events, as opposed to $13 \%$ of adults $(p<0.001)$; sudden death/life threatening illness of a close person was declared by $6.1 \%$ of young people and $3.2 \%$ of adults $(p=0.017)$. Young people were more prone to car and motorcycle accidents than adults though not statistically significant ( $2.3 \%$ vs. $1.0 \%, p<0.074$ ), and more likely to witness someone being killed or injured $(7.0 \%$ vs. $2.6, p<0.001)$.

Findings from the logistic regression models are presented in Table 3. As a result of the logistic regression models, through which the association of traumatic events and mental disorders was stratified by age groups (young people and adults) and controlled for potential confounding factors, we found the following associations: Alcohol related disorders were associated with assaultive violence among young people $(\mathrm{OR}=3.4 ; 95 \%$
$\mathrm{CI}=1.36$ to $8.52 ; p=0.004)$ and adults $(\mathrm{OR}=2.38 ; 95 \%$ $\mathrm{CI}=1.23$ to $4.61 ; p=0.002)$. Among adults, alcohol related disorders were also associated with other injury or shocking events $(\mathrm{OR}=1.51 ; 95 \% \mathrm{CI}=0.74$ to 3.05 ; $p=0.030$ ).

Phobic/anxiety disorders were associated with other injury or shocking events among young people (OR = $1.28 ; 95 \% \mathrm{CI}=0.67$ to $2.44 ; p=0.025)$. Among adults, these disorders were associated with exposure to assaultive violence $(\mathrm{OR}=1.23 ; 95 \% \mathrm{CI}=0.94$ to $1.61 ; p=0.001)$, other injury or shocking events $(\mathrm{OR}=1.31 ; 95 \% \mathrm{CI}=0.95$ to $1.79 ; p=<0.001)$, and sudden death/life threatening illness of a close person $(\mathrm{OR}=1.35 ; 95 \% \mathrm{CI}=1.06$ to1.71; $p=0.003$ ).

Major depressive disorder was associated with exposure to assaultive violence among young people $(\mathrm{OR}=2.27 ; 95 \% \mathrm{CI}=1.09$ to $4.74 ; p=0.004)$ and adults $(\mathrm{OR}=1.28 ; 95 \% \mathrm{CI}=0.85$ to $1.93 ; p=0.009)$. The same condition was associated with other injury or shocking events in adults $(\mathrm{OR}=1.65 ; 95 \% \mathrm{CI}=1.04$ to $2.62 ; p=0.001$ ).

The logistic regression analyses also show that female gender is associated with a lower likelihood of alcohol-related disorders among adults $(\mathrm{OR}=0.35$; $95 \% \mathrm{CI}=0.19$ to $0.63 ; p=0.001$ ); with a higher likelihood of anxiety disorders among youth $(\mathrm{OR}=3.08$; $95 \% \mathrm{CI}=1.70$ to $5.58 ; p<0.001)$ and among adults $(\mathrm{OR}=2.57 ; 95 \% \mathrm{CI}=1.83$ to $3.62 ; p<0.001)$; and with a higher likelihood of depressive disorder among youth $(\mathrm{OR}=5.97 ; 95 \% \mathrm{CI}=2.27$ to $15.71 ; p<0.001)$, and among adults (OR $=3.0$; $95 \% \mathrm{CI}=1.99$ to $4.69 ; p<0.001)$. Education level among adults, expressed as number of years of schooling, was negatively associated with alcohol related disorders $(\mathrm{OR}=0.92 ; 95 \% \mathrm{CI}=0.86$ to $0.99 ; p=0.018)$, and with anxiety disorders $(\mathrm{OR}=0.97 ; 95 \% \mathrm{CI}=0.94$ to $1.0 ; p=0.039)$.

\section{Discussion}

To the best of our knowledge, this is the first study that provides a comprehensive assessment of exposure to violence and other traumatic events among young people. Exposure to traumatic events in the 12 months before to the interview was significantly higher among young people (32.1\% vs. $20.6 \%)$. Overall, young people were highly exposed to other injury and shocking events (20.1\%), assaultive violence (13.4\%), and sudden death/ life threatening illness of a close person (6.1 \%). Thus, our results confirm that exposure to violence and other traumatic events is greater among young people than adults. It has been proposed that youths have a higher risk of facing violence worldwide [2, 14, 38, 39]. However, most of the evidence on violence exposure is based on homicide rates [15, 39], which is recognized that homicide is one of the most comparable and accurate 
Table 2 Prevalence of 1-year DSM-IV mental disorders and exposure to violence and other traumatic events

\begin{tabular}{|c|c|c|c|c|}
\hline & $15-24$ & $25-44$ & $P$ value & OR $(95 \% \mathrm{Cl})$ \\
\hline \multicolumn{5}{|l|}{ One-year mental disorders } \\
\hline Alcohol related disorders & $26(5.4)$ & $64(2.5)$ & 0.032 & $0.6(0.4-0.92)$ \\
\hline Phobic/anxiety disorders & $74(15.8)$ & $352(17.3)$ & 0.543 & $1.21(0.93-1.6)$ \\
\hline Major depressive disorder & $32(4.7)$ & $190(9.0)$ & 0.004 & $1.52(1.04-2.21)$ \\
\hline Assaultive violence & $59(13.4)$ & $165(8.6)$ & 0.012 & $0.67(0.5-1.0)$ \\
\hline War experience & $0(0.0)$ & $0(0.0)$ & 0 & $0(0-0)$ \\
\hline Being attacked without weapon & $8(1.8)$ & $16(0.8)$ & 0.142 & $0.5(0.2-1.2)$ \\
\hline Being attacked with weapon & $15(3.1)$ & $44(2.3)$ & 0.435 & $0.72(0.4-1.35)$ \\
\hline Being kidnapped, or held captive & $1(0.1)$ & $1(0.1)$ & 0.961 & $0.24(0.01-4.1)$ \\
\hline Fast kidnap & $1(0.1)$ & $0(0)$ & 0.035 & $N A^{a}$ \\
\hline Torture/terrorism & $2(0.7)$ & $0(0)$ & 0.014 & $N A^{a}$ \\
\hline Death threats & $12(3.1)$ & $43(2.1)$ & 0.308 & $1(0.46-1.68)$ \\
\hline Conflict between gangs/drug dealers' & $0(0.0)$ & $5(0.3)$ & 0.360 & $N A^{a}$ \\
\hline Rape & $0(0.0)$ & $0(0.0)$ & 0 & $N A^{a}$ \\
\hline Sexual molestation & $0(0)$ & $2(4.92-04)$ & 0.504 & $N A^{a}$ \\
\hline Being beaten-up by parents/relatives & $7(1.3)$ & $7(0.4)$ & 0.075 & $0.24(0.1-0.71)$ \\
\hline Being beaten up by an intimate partner & $6(1.4)$ & $20(0.8)$ & 0.313 & $0.82(0.33-2.05)$ \\
\hline Being beaten up by anyone else than family/partner & $3(0.3)$ & $3(0.2)$ & 0.541 & $0.24(0.05-1.22)$ \\
\hline Having one's house broken into while at home & $17(2.4)$ & $25(1.0)$ & 0.057 & $0.52(0.23-1.21)$ \\
\hline Blackmailing telephone calls & $13(3.1)$ & $55(2.9)$ & 0.925 & $1.05(0.59-1.88)$ \\
\hline Other injury or shocking events & $106(20.1)$ & $270(13.0)$ & 0.001 & $0.6(0.45-0.73)$ \\
\hline Car/motorcycle accident & $11(2.3)$ & $22(1.0)$ & 0.074 & $0.5(0.24-1)$ \\
\hline Accidents other than car/motorcycle & $1(0.1)$ & $7(0.5)$ & 0.159 & $1.73(0.2-14.7)$ \\
\hline Fire, flood, natural disaster & $2(0.7)$ & $11(0.9)$ & 0.745 & $1.4(0.27-6.92)$ \\
\hline Witnessing someone being killing or injured & $32(7.0)$ & $58(2.6)$ & $<0.001$ & $0.43(0.27-0.69)$ \\
\hline Witnessing bank robbery & $2(0.6)$ & $13(0.9)$ & 0.640 & $1.61(0.34-7.63)$ \\
\hline Witnessing a shoot-out or being victim of stray bullet & $18(3.6)$ & $32(1.7)$ & 0.030 & $0.43(0.22-0.83)$ \\
\hline Witnessing domestic violence during childhood & $3(0.3)$ & $3(0.3)$ & 0.764 & $0.25(0.066-0.91)$ \\
\hline Having one's house broken into while not at home & $6(0.7)$ & $27(1.3)$ & 0.155 & $1.12(0.42-3)$ \\
\hline Seeing or touching a corpse & $38(6.8)$ & $90(4.1)$ & 0.040 & $0.6(0.4-0.82)$ \\
\hline Witnessing atrocities, slaughter, massacre & $6(1.1)$ & $20(1.0)$ & 0.824 & $0.82(0.35-1.94)$ \\
\hline Human made disaster & $2(0.7)$ & $5(0.3)$ & 0.335 & $0.62(0.14-2.7)$ \\
\hline Witnessing crime organizations' & $4(0.4)$ & $13(0.3)$ & 0.600 & $0.8(0.3-2.44)$ \\
\hline Sudden death/life threatening illness of a close person & $93(7.3)$ & $130(4.1)$ & 0.013 & $0.6(0.4-0.93)$ \\
\hline Sudden unexpected death of a close person & $30(6.1)$ & $73(3.2)$ & 0.017 & $0.6(0.37-0.92)$ \\
\hline Child with life threatening illness or injury & $7(1.3)$ & $22(0.9)$ & 0.587 & $0.8(0.35-1.7)$ \\
\hline Any traumatic events & $158(32.1)$ & $428(20.67)$ & 0.001 & $0.6(0.46-0.73)$ \\
\hline
\end{tabular}

${ }^{\mathrm{a}} \mathrm{NA}=\mathrm{OR}$ and $95 \% \mathrm{Cl}$ not available as number of cases in at least one of the categories equal 0 (zero)

indicators for measuring violence [40]. Nonetheless, the World Health Organization recognizes that homicides represent only a fraction of overall violence, and suggests that more precise data of non-fatal violence must be gathered [15].

Our results validate the idea that psychiatric morbidity patterns are different among young people and adults.
Phobic/anxiety disorders were the most prevalent diagnosis in both groups. Alcohol related disorders were the second most frequent diagnosis among young people, and were almost twice more prevalent among young people than adults (5.3\% vs. $2.9 \%$ ), whereas depression was twice more prevalent among adults than young people (9.0 \% vs. $4.7 \%)$. The higher prevalence of alcohol-related disorders 
Table 3 Multivariate logistic regression model of the association between exposure to traumatic events and mental disorders

\begin{tabular}{|c|c|c|c|c|c|c|c|c|}
\hline & \multicolumn{8}{|c|}{ Assaultive violence } \\
\hline & \multicolumn{4}{|c|}{$15-24$ years } & \multicolumn{4}{|c|}{$25-75$ years } \\
\hline & No & Yes & O.R $(95 \% \mathrm{Cl})$ & $P$ & No & Yes & O.R (95 \% Cl) & $P$ \\
\hline Alcohol related disorders & $8(2.9)$ & $18(9.0)$ & $3.4(1.36-8.52)$ & 0.004 & $13(1.2)$ & $51(4.0)$ & $2.38(1.23-4.61)$ & 0.002 \\
\hline Phobic/anxiety disorders & $12(3.8)$ & $13(6.8)$ & $1.68(1.01-2.78)$ & 0.120 & $56(7.5)$ & $122(10.5)$ & $1.23(0.94-1.61)$ & 0.001 \\
\hline \multirow[t]{4}{*}{ Major depressive disorder } & $12(3.2)$ & $20(7.1)$ & $2.27(1.09-4.74)$ & 0.004 & $63(8.0)$ & $127(9.8)$ & $1.28(0.85-1.93)$ & 0.009 \\
\hline & \multicolumn{8}{|c|}{ Other injury or shocking events } \\
\hline & \multicolumn{4}{|c|}{$15-24$ years } & \multicolumn{4}{|c|}{$25-75$ years } \\
\hline & No & Yes & O.R $(95 \% \mathrm{Cl})$ & $P$ & No & Yes & O.R $(95 \% \mathrm{Cl})$ & $P$ \\
\hline Alcohol related disorders & $6(1.9)$ & $20(7.3)$ & $1.39(0.44-4.38)$ & 0.253 & $9(1.4)$ & $55(3.4)$ & $1.51(0.74-3.05)$ & 0.030 \\
\hline Phobic/anxiety disorders & $4(2.5)$ & $21(6.4)$ & $1.28(0.67-2.44)$ & 0.025 & $29(5.3)$ & $149(10.7)$ & $1.31(0.95-1.79)$ & $<0.001$ \\
\hline \multirow[t]{4}{*}{ Major depressive disorder } & $5(2.3)$ & $27(6.1)$ & $2.36(0.51-10.85)$ & 0.114 & $33(5.6)$ & $157(10.3)$ & $1.65(1.04-2.62)$ & 0.001 \\
\hline & \multicolumn{8}{|c|}{ Sudden death or illness of a close person } \\
\hline & \multicolumn{4}{|c|}{$15-24$ years } & \multicolumn{4}{|c|}{$25-75$ years } \\
\hline & No & Yes & O.R $(95 \% \mathrm{Cl})$ & $\mathrm{P}$ & No & Yes & O.R (95 \% Cl) & $P$ \\
\hline Alcohol related disorders & $20(6.2)$ & $6(3.6)$ & $0.62(0.22-1.72)$ & 0.518 & $32(2.9)$ & $32(2.9)$ & $1.11(0.65-1.88)$ & 0.215 \\
\hline Phobic/anxiety disorders & $14(4.5)$ & $11(5.9)$ & $1.15(0.70-1.91)$ & 0.155 & $79(7.5)$ & $99(11.4)$ & $1.35(1.06-1.71)$ & 0.003 \\
\hline Major depressive disorder & $19(4.1)$ & $13(6.1)$ & $1.17(0.53-2.55)$ & 0.345 & $92(7.4)$ & $98(11.0)$ & $1.03(0.71-1.5)$ & 0.120 \\
\hline
\end{tabular}

among the youth in our study supports the assumption that harmful use of alcohol among young people living in urban centres of the low- and middle-income countries is very frequent. It has been suggested that young people usually experiment with alcohol to a great extent at this stage due to bio-psychosocial changes they experience [19, 20], as well as due to their natural drive to search for novelty [3]. It has also been proposed that risk factors such as family history of alcoholism, disturbed childhood behaviour, neuropsychological and/or developmental problems, poor relationships with colleagues and family, as well as unfavourable and violent neighbourhoods might interact individually or in group with genetic vulnerability to increase the incidence of alcohol abuse among young people. Some of the potentially negative consequences of abusive consumption of alcohol among adolescents include decreased self-control and increased risk behaviours. Use of Alcohol has been shown to be the leading cause of injuries, traffic accidents, violence and premature deaths around the world $[2,12,14]$.

The higher prevalence of depression among adults may be a result of the usually later onset of this disease $[19,20]$, which results in depressive disorder being more prevalent in later stages of life $[17,41]$.

Our logistic regression models showed that the only demographic characteristic associated with psychiatric disorders among the youth was female gender, which was associated with an increased risk of anxiety and depression. Among adults, female gender was associated with a lower likelihood of alcohol-related disorders, and with an increased risk of anxiety and depression. Higher education level was also related with a lower likelihood of alcohol-related disorders and anxiety among adults. Both gender and education have consistently been found to be associated with the prevalence of mental disorders [42-44].

Additionally, we also tested the hypothesis that patterns of association between traumatic events and psychiatric morbidity would be different among young people and adults. Results showed that assaultive violence was associated with alcohol related disorders and major depressive disorder in young people and adults. Among young people, other injury or shocking events were associated with a higher probability of developing phobic/anxiety disorders, whereas the same type of event in adults was associated with an increase in the three psychiatric disorders under comparison. These results suggest that, whereas both groups are equally affected by the exposure to assaultive violence, the impact of other injury or shocking events seems to be greater among adults than among young people. One possible explanation relies on the cumulative effect of traumatic experiences over time, which may undermine one's ability to cope with adversity [11, 17]. This may be due to the sensitization effect, which leads individuals previously exposed to traumatic events to have a greater responsiveness to subsequent stressors $[2,9,41,44]$.

The study's cross-sectional design does not allow to discard reverse causality in the association between traumatic events and mental disorders. Evidence suggests that exposure to violence and other traumatic events favour the development of mental disorders [4]. However, mental 
disorders, particularly those associated with use of alcohol and drugs, may increase the risk of victimization $[6,7]$. To minimize the possibility of reverse causality, statistical models included only traumatic events that occurred more than 12 months before the interviews, whereas psychiatric diagnoses in the last year were included in the analysis as dependent variables. Another potential limitation is that results were based on the CIDI 2.1, which is a standardized questionnaire that may not be accurate due to memory bias, besides being conducted by lay interviewers. Moreover, due to Brazilian heterogeneity, results may not be generalizable to the entire country, particularly to small and medium cities, where socioeconomic patterns and life styles may differ significantly from larger urban centres.

\section{Conclusions}

This study provides evidence that young people are more exposed to violence and other traumatic events than adults, thus developing strategies to reduce violence amongst young people and to provide care for exposed victims in this age group is paramount.

A number of interventions to reduce vulnerability among adolescents and young adults has been tested. For instance, in Australia, Canada, the United Kingdom, and the United States of America (USA), it was shown that raising the minimum legal drinking age and having graduated licensing policies for teen drivers can reduce harmful use of alcohol, traffic accidents and criminality $[12,24]$, whereas in the USA, Fonagy and colleagues tested a manualized school psychiatric consultation program and the Creating a Peaceful Learning Environment, which is a manualized psychodynamic intervention, and concluded that both interventions were effective in reducing children's experience of aggression and victimization, when compared to no intervention [23].

The results also suggest that the impact of exposure to violence on mental health is greater among adults, providing evidence that combating violence against young people could significantly reduce psychiatric morbidity later in life.

\section{Ethics approval and consent to participate}

The study protocol was approved by the Research Ethics Committee of the Federal University of São Paulo, including Informed Consent Forms, data collection questionnaires, participants' recruiting procedures, interview procedures and actions to protect privacy, integrity and rights of participants. Participants were interviewed only after signing the informed consent forms. For participants who were between 15 and 17 years of age, a legal guardian signed the consent form.

\section{Consent for publication}

Not applicable

\section{Availability of data and materials}

Data and materials are available upon request to Wagner Ribeiro, PhD. (W.Silva-Ribeiro@Ise.ac.uk).

\section{Abbreviations}

CIDI 2.1: Composite International Diagnostic Interview, version 2.1; DSMIV: Diagnostic and Statistical Manual of Mental Disorders, 4th Edition; PTSD: posttraumatic stress disorder; OR: Odds Ratio; P: Value P; Cl: confidence interval; USA: United States of America; FAPESP: State of São Paulo Funding Agency; CNPq: National Research and Technology Development Council; CAPES: Coordination for Improvement of Faculty Personnel; PEC-

PG: Students-Agreement Program Postgraduate.

\section{Competing interests}

The authors declare that they have no competing interests.

\section{Authors' contributions}

DJV, WSR and JJM conceived the article; DJV carried out the review and prepared the manuscript; WSR, ESC and JJM contributed to the statistical analysis; WSR and JJM supervised the review and the manuscript preparation; DJV, WSR, ESC and JJM contributed to the discussion, conclusions and final revision of the article. All of the authors read and approved the final manuscript. JJM, WSR, ESC, SBA, MIQ, MFM, and RAB conceived and designed the original study. All authors approved the final version.

\section{Acknowledgements}

Dr. Denisse Jaen Varas was supported by Students-Agreement Program Postgraduate - PEC-PG from CAPES/CNPq - Brazil, which provided DJV with a 2-year Master's scholarship at Universidade Federal de São Paulo, Brazil.

\section{Funding}

This study was funded by the State of São Paulo Funding Agency - FAPESP (www.fapesp.br) through the grant: 2004/15039-0, and the National Research and Technology Development Council - CNPq (www.cnpq.br) through the grant: 420122/2005-2. Wagner Ribeiro received a doctorate scholarship from CNPQ (141467/2007-0) and a 1-year scholarship from the Brazilian Coordination for Improvement of Faculty Personnel - CAPES (www.capes.gov.br), Proc.4516/07-9, to spend 1 year at the Institute of Psychiatry - King's College London. JJM is a I-A researcher from CNPq.

\section{Author details}

${ }^{1}$ Departamento de Psiquiatria, Universidade Federal de São Paulo, Rua Borges Lagoa, 570, São Paulo, SP 04038-000, Brazil. ${ }^{2}$ Health Service and Population Research Department, King's College London, Institute of Psychiatry, London, United Kingdom. ${ }^{3}$ Fundação Oswaldo Cruz, Escola Nacional de Saúde Pública, Rio de Janeiro, Brazil. ${ }^{4}$ London School of Economics and Political Science, Personal Social Services Research Unit London, United Kingdom.

Received: 9 May 2015 Accepted: 4 May 2016

Published online: 07 June 2016

References

1. Gore FM, Bloem PJ, Patton GC, Ferguson J, Joseph V, Coffey C, Sawyer SM, Mathers CD. Global burden of disease in young people aged 10-24 years: a systematic analysis. Lancet. 2011;377(9783):2093-102.

2. Fatusi $A O$, Hindin MJ. Adolescents and youth in developing countries: Health and development issues in context. J Adolesc. 2010;33(4):499-508.

3. Blum RW. Young people: not as healthy as they seem. Lancet. 2009: 374(9693):853-4.

4. Blum RW, Bastos Fl, Kabiru CW, Le LC. Adolescent health in the 21st century. Lancet. 2012;379(9826):1567-8.

5. Lee FS, Heimer H, Giedd JN, Lein ES, Sestan N, Weinberger DR, Casey BJ. Mental health. Adolescent mental health-opportunity and obligation. Science. 2014;346(6209):547-9.

6. Paus $T$, Keshavan M, Giedd JN. Why do many psychiatric disorders emerge during adolescence? Nat Rev Neurosci. 2008;9(12):947-57. 
7. Casey BJ, Getz S, Galvan A. The adolescent brain. Dev Rev. 2008;28(1):62-77.

8. Giedd JN. Structural magnetic resonance imaging of the adolescent brain. Ann N Y Acad Sci. 2004;1021:77-85.

9. Sawyer SM, Afifi RA, Bearinger LH, Blakemore SJ, Dick B, Ezeh AC, Patton GC. Adolescence: a foundation for future health. Lancet. 2012;379(9826):1630-40.

10. Casey BJ, Jones RM, Hare TA. The adolescent brain. Ann N Y Acad Sci. 2008. 1124:111-26.

11. Arnett JJ. Adolescent storm and stress, reconsidered. Am Psychol. 1999; 54(5):317-26.

12. Catalano RF, Fagan AA, Gavin LE, Greenberg MT, Irwin Jr CE, Ross DA, Shek DT. Worldwide application of prevention science in adolescent health. Lancet. 2012;379(9826):1653-64.

13. National Research $C$, Institute of Medicine Committee on the Prevention of Mental D, Substance Abuse Among Children Y, Young Adults: Research A, Promising I. The National Academies Collection: Reports funded by National Institutes of Health. In: O'Connell ME, Boat T, Warner KE, editors. Preventing Mental, Emotional, and Behavioral Disorders Among Young People: Progress and Possibilities. Washington: National Academies Press (US) National Academy of Sciences; 2009.

14. Blum RW, Nelson-Mmari K. The health of young people in a global context. J Adolesc Health. 2004;35(5):402-18

15. World Health Organization: World report on violence and health. In. Geneva; 2002.

16. Wittchen HU, Nelson CB, Lachner G. Prevalence of mental disorders and psychosocial impairments in adolescents and young adults. Psychol Med. 1998;28(1):109-26.

17. Perkonigg A, Kessler RC, Storz S, Wittchen HU. Traumatic events and posttraumatic stress disorder in the community: prevalence, risk factors and comorbidity. Acta Psychiatr Scand. 2000;101(1):46-59.

18. Medina-Mora Icaza ME, Borges-Guimaraes G, Lara C, Ramos-Lira L, Zambrano J, Fleiz-Bautista C. Prevalence of violent events and post-traumatic stress disorder in the Mexican population. Salud Publica Mex. 2005;47(1):8-22.

19. Ribeiro WS, Andreoli SB, Ferri CP, Prince M, Mari JJ. Exposure to violence and mental health problems in low and middle-income countries: a literature review. Rev Bras Psiquiatr. 2009;31 Suppl 2:S49-57.

20. Ribeiro WS, Mari Jde J, Quintana MI, Dewey ME, Evans-Lacko S, Vilete LM, Figueira I, Bressan RA, de Mello MF, Prince M, et al. The impact of epidemic violence on the prevalence of psychiatric disorders in Sao Paulo and Rio de Janeiro, Brazil. PLoS One. 2013;8(5):e63545.

21. Tremblay RE, Szyf M. Developmental origins of chronic physical aggression and epigenetics. Epigenomics. 2010;2(4):495-9.

22. Bordin IA, Duarte CS, Peres CA, Nascimento R, Curto BM, Paula CS. Severe physical punishment: risk of mental health problems for poor urban children in Brazil. Bull World Health Organ. 2009;87(5):336-44.

23. Fonagy P, Twemlow SW, Vernberg EM, Nelson JM, Dill EJ, Little TD, Sargent JA. A cluster randomized controlled trial of child-focused psychiatric consultation and a school systems-focused intervention to reduce aggression. J Child Psychol Psychiatry. 2009;50(5):607-16.

24. World Health Organization: Health for the World's Adolescents: A second chance in the second decade. In.; 2014.

25. Zlotnick C, Johnson J, Kohn R, Vicente B, Rioseco P, Saldivia S. Epidemiology of trauma, post-traumatic stress disorder (PTSD) and co-morbid disorders in Chile. Psychol Med. 2006;36(11):1523-33.

26. Medina-Mora ME, Borges G, Benjet C, Lara C, Berglund P. Psychiatric disorders in Mexico: lifetime prevalence in a nationally representative sample. Br J Psychiatry. 2007;190:521-8.

27. Eaton NR, Keyes KM, Krueger RF, Balsis S, Skodol AE, Markon KE, Grant BE, Hasin DS. An invariant dimensional liability model of gender differences in mental disorder prevalence: evidence from a national sample. J Abnorm Psychol. 2012;121(1):282-8.

28. Perry B. The Neurodevelopmental Impact of Violence in Childhood, Eds., D. Schetky and E.P. Benedek edn; 2001.

29. Spenrath MA, Clarke ME, Kutcher S. The Science of Brain and Biological Development: Implications for Mental Health Research, Practice and Policy. J Can Acad Child Adolescent Psychiatry. 2011;20(4)298-304.

30. National Institutes of Health (US), Biological Sciences Curriculum Study. Information about Mental IIIness and the Brain. In: NIH Curriculum Supplement Series: Biological Sciences Curriculum Study. 2007.

31. Kish L. A Procedure for Objective Respondent Selection within the Household. Journal of the American Statistical Association. 1949:44(247):380-7.
32. World Health Organization: Composite International Diagnostic Interview. Version 2.1. In. Geneva; 1997.

33. Rubio-Stipec M, Bravo M, Canino G. The Composite International Diagnostic Interview (CIDI): an epidemiologic instrument suitable for using in conjunction with different diagnostic systems in different cultures. Acta Psiquiatr Psicol Am Lat. 1991;37(3):191-204.

34. Quintana MI, Gastal FL, Jorge MR, Miranda CT, Andreoli SB. Validity and limitations of the Brazilian version of the Composite International Diagnostic Interview (CIDI 2.1). Rev Bras Psiquiatr. 2007;29(1):18-22.

35. Andrade LH, Wang YP, Andreoni S, Silveira CM, Alexandrino-Silva C, Siu ER, Nishimura R, Anthony JC, Gattaz WF, Kessler RC, et al. Mental disorders in megacities: findings from the Sao Paulo megacity mental health survey, Brazil. PLoS One. 2012;7(2):e31879.

36. Norris FH, Murphy AD, Baker CK, Perilla JL, Rodriguez FG, Rodriguez Jde J. Epidemiology of trauma and posttraumatic stress disorder in Mexico. J Abnorm Psychol. 2003;112(4):646-56.

37. Breslau N, Peterson EL, Poisson LM, Schultz LR, Lucia VC. Estimating posttraumatic stress disorder in the community: lifetime perspective and the impact of typical traumatic events. Psychol Med. 2004;34(5):889-98.

38. Patton GC, Coffey C, Sawyer SM, Viner RM, Haller DM, Bose K, Vos T, Ferguson J, Mathers CD. Global patterns of mortality in young people: a systematic analysis of population health data. Lancet. 2009:374(9693):881-92.

39. World Health Organization: The global burden of disease: 2004 update. In.; 2004.

40. United Nations Office on drugs and crime: Global study on homicide. In. Edited by UNODOC; 2013.

41. Kieling C, Baker-Henningham H, Belfer M, Conti G, Ertem I, Omigbodun O, Rohde LA, Srinath S, Ulkuer N, Rahman A. Child and adolescent mental health worldwide: evidence for action. Lancet. 2011;378(9801):1515-25.

42. Kessler RC, Berglund P, Demler O, Jin R, Merikangas KR, Walters EE. Lifetime prevalence and age-of-onset distributions of DSM-IV disorders in the National Comorbidity Survey Replication. Arch Gen Psychiatry. 2005;62(6):593-602.

43. Kessler RC, Angermeyer M, Anthony JC, DE Graaf R, Demyttenaere K, Gasquet I, DE Girolamo G, Gluzman S, Gureje O, Haro JM, et al. Lifetime prevalence and age-of-onset distributions of mental disorders in the World Health Organization's World Mental Health Survey Initiative. World Psychiatry. 2007:6(3):168-76.

44. Kessler RC, Wang PS. The descriptive epidemiology of commonly occurring mental disorders in the United States. Annu Rev Public Health. 2008:29:115-29.

\section{Submit your next manuscript to BioMed Central and we will help you at every step:}

- We accept pre-submission inquiries

- Our selector tool helps you to find the most relevant journal

- We provide round the clock customer support

- Convenient online submission

- Thorough peer review

- Inclusion in PubMed and all major indexing services

- Maximum visibility for your research

Submit your manuscript at www biomedcentral.com/submit

C BioMed Central 